\title{
Hibiscus sabdariffa Linn. improves the aortic damage in diabetic rats by acting as antioxidant
}

\author{
Satirah Zainalabidin, Siti Balkis Budin", Nur Najmi Mohamad Anuar, Nur Afizah Yusoff, Nur Liyana Mohammed Yusof \\ Biomedical Science Programme, School of Diagnostic and Applied Health Sciences, Faculty of Health Sciences, Universiti Kebangsaan Malaysia, 50300
} Kuala Lumpur, Malaysia.

\begin{tabular}{l}
\hline ARTICLE INFO \\
\hline Article history: \\
Received on: 23/08/2017 \\
Accepted on: 23/11/2017 \\
Available online: 28/01/2018 \\
\hline Key words: \\
Antioxidant; diabetes; free \\
radical; Hibiscus sabdariffa \\
Linn.; oxidative damage
\end{tabular}

\begin{abstract}
Chronic hyperglycaemia produces excessive free radicals which could lead to diabetic complications. Hibiscus sabdariffa Linn. is proven to have high antioxidant and antihyperlipidemic properties. The aim of the study was to investigate the effects of $H$. sabdariffa polyphenol-rich extract (HPE) in the aorta of diabetic rats. Twenty-four male rats were randomly divided into three groups, i.e. non-diabetes mellitus (NDM), diabetes mellitus (DM) and diabetes mellitus with HPE (DM + HPE). HPE at $100 \mathrm{mg} / \mathrm{kg}$ or saline as control vehicle were administered daily through oral gavage for 28 days prior to sacrification and the aorta was isolated for further analysis. The glucose level in DM + HPE was significantly lower compared to DM, indicating its potential as an antidiabetic agent. Conversely, catalase (CAT), superoxide dismutase (SOD) activity and the level of glutathione (GSH) in DM + HPE were significantly higher than DM. The level of malondialdehyde (MDA) and protein carbonyl were significantly lower in DM + HPE than DM. Lipid profile analysis demonstrated a significant decrease in triglyceride, total cholesterol and LDL-C in DM + HPE compared to DM, however, HDL-C was significantly increased. Microscopic observation showed a disrupted morphology of the thoracic aorta in diabetic rats. HPE may exert protective effects by acting as an antidiabetic, antihyperlipidemic and antioxidant agent to the thoracic aorta in diabetic rats.
\end{abstract}

\section{INTRODUCTION}

Diabetes mellitus (DM) is a chronic metabolic disorder in which prevalence has been growing steadily in our society. This disease occurs when the body could not produce sufficient insulin hormone or when this hormone does not work effectively (Beckman et al., 2013). Poorly managed diabetes leads to serious complications affecting different organs, such as neuropathy, nephropathy, and retinopathy (Inzucchi et al., 2010). Eventually, atherosclerosis would rise as a major threat to the macro vasculature problem which lead to morbidity and mortality in diabetic patients (Dokken, 2008).

Oxidative stress is a common feature of diabetes mellitus (DM), in which the activity of the antioxidant system is over-

\footnotetext{
${ }^{*}$ Corresponding Author

Siti Balkis Budin, Biomedical Science Programme, School of Diagnostic and Applied Health Sciences, Faculty of Health Sciences, Universiti Kebangsaan Malaysia, 50300 Kuala Lumpur, Malaysia.

E-mail: balkis@ukm.edu.my
}

whelmed by excessive reactive oxygen species (ROS) production (Valko et al., 2007). Chronic hyperglycaemia increases the generation of free radicals through the activation of polyol pathway, formation of advanced glycosylation end products, activation of protein kinase $\mathrm{C}$ and hexosamine pathways (Brownlee, 2005). Oxidation of lipids, proteins and other macromolecules such as DNA occurs during the development of diabetes and during the subsequent complications (Brownlee, 2005). Antioxidant defence mechanisms involve both enzymatic and non-enzymatic strategies. Enzymatic antioxidants include superoxide dismutase (SOD), catalase (CAT) and glutathione (GSH). As for common non-enzymatic antioxidants, these include the vitamins $\mathrm{A}, \mathrm{C}$ and $\mathrm{E}$ as well as cofactors like folic acid, uric acids and vitamins B1, B2, B6 and B12 (Maritim et al., 2003).

Hibiscus sabdariffa Linn. or Roselle from the Malvaceae family is one of the most common flowering plant grown in Malaysia. It has high nutritional values especially in the leaves, calyx parts and seeds. The leaves, calyx and seeds are known for 
its high nutritional values with the calyx commonly being used in the preparation of various drinks, jam and jellies (Lin et al., 2012). It is also rich in organic acids such as citric acid, ascorbic acid, pectin and polyphenols which include anthocyanin, phenolic acids, flavonoids and others (Lin et al., 2012). Previous studies have shown that Roselle has great potential as antioxidant (Mossalam et al., 2011), nephroprotective (Olalye \& Rocha, 2007), hypolipidemic (Joshi \& Parle, 2006), anti-obesity (Herranz-Lopez et al., 2012) and antihypertensive (Mahadevan et al., 2009). This present study is aimed to observe the effects of Hibiscus sabdariffa Linn. polyphenol-rich extract (HPE) in the thoracic aorta of streptozotocin (STZ)-induced diabetic rats.

\section{MATERIALS AND METHODS}

\section{Plant extraction}

Hibiscus sabdariffa Linn. calyces (specimen voucher: UKMB 40308) was procured from Ai Agro Marketing, Terengganu, Malaysia. About 100 grams of dried ground H. sabdariffa Linn. calyx were extracted with $50 \mathrm{~mL}$ of an HPLC-grade methanol $99.9 \%$ for analytical grade (Thermo Fisher Scientific, UK) and stirred in a $60^{\circ} \mathrm{C}$ water bath for 30 minutes. The extract was filtered through a Whatman No. 4 filter paper and the residue was extracted twice using similar procedure as above. The extracts were pooled and evaporated using a rotary evaporator (model R-200, Buchi, Switzerland). Residues were solubilized in $200 \mathrm{~mL}$ of distilled water and the resulting aqueous solution were partitioned successively with n-hexane and ethyl acetate. Using a rotary evaporator (model R-200, Buchi, Switzerland), the ethyl acetate soluble fraction was evaporated to dryness. The $H$. $s a b$ dariffa Linn. polyphenol-rich extract (HPE) was stored at $-20^{\circ} \mathrm{C}$ for further use.

\section{Animal work}

Twenty-four male Sprague-Dawley rats weighing 250300 grams were obtained from Laboratory Animal Resources Unit, Universiti Kebangsaan Malaysia (UKM). These rats were placed in polypropylene cages ( 2 animals per cage) and kept under standard laboratory conditions with a 12 hours' light/dark cycle. The rats also were fed with commercial pellet diet and allowed free access to water $\mathrm{ad}$ libitum throughout the experiment. Animals were acclimatized to the experimental condition for 1 week prior to experiment and all procedures with animals were strictly adhered to the guidelines of Universiti Kebangsaan Malaysia Animal Ethics Committee (UKMAEC). The animal ethic approval number was FSK/2015/BALKIS/11-FEB./643FEB.-2015-FEB.-2018.

\section{Induction of diabetes}

Diabetes was induced through a single intraperitoneal injection of freshly prepared streptozotocin (STZ) $(60 \mathrm{mg} / \mathrm{kg})$ in overnight fasted rats (Bagri et al., 2009). After 72 hours, fasting blood glucose level were measured using glucometer (ACCUCHEK $\AA$ Performa, Roche Diagnostics). Rats with blood glucose levels above $15 \mathrm{mmol} / \mathrm{L}$ were considered to be diabetic and selected to be used in this research.

\section{Experimental design}

The animals were randomly divided into three groups ( $n=8$ per group), which are the non-diabetics control (NDM), diabetes mellitus (DM) and diabetes mellitus supplemented with HPE (DM + HPE). NDM and DM group received $0.9 \% \mathrm{NaCl}$ (BDH Laboratory Supplies, UK), while for DM + HPE group. HPE was administered through oral gavage at $100 \mathrm{mg} / \mathrm{kg}$ daily for 28 consecutive days (Ramalingam et al., 2016). HPE was re-dissolved in distilled water before used (Lim et al., 2017). Blood glucose level and body weight were recorded weekly throughout the study.

\section{Sample preparation}

At the end of the experiment period, the rats were fasted overnight and blood was drawn via orbital sinus, which then sacrificed and thoracic aorta was isolated. The upper third of the thoracic aorta was taken for electron microscopic examination and the remaining was used for homogenates preparation as described by previous study (Upston et al., 2001). The homogenate was stored at $-80^{\circ} \mathrm{C}$ for further analysis.

\section{Blood glucose and lipid profile}

Fasting blood glucose was determined using glucose oxidase kits (BioSystems SA, Spain), while plasma triglyceride, total cholesterol and high-density lipoprotein (HDL-C) were measured using commercial kits (Teco Diagnostics, Anaheim). Low-density lipoprotein (LDL-C) concentrations were determined using methods described by previous study (Friedewald et al., 1972) and the results were expressed as $\mathrm{mmol} / \mathrm{L}$.

\section{Oxidative stress assessment}

Malondialdehyde (MDA) is a marker to determine lipid peroxidation (Stocks \& Dormandy, 1971) in which MDA reacts to form thiobarbituric acid reactive species (TBARS) chromogen and its absorbance was measured spectrophotometerically (UV 160A, Shidmazu, Japan) at $532 \mathrm{~nm}$. The results were expressed as $\mathrm{nmol} / \mathrm{g}$ of protein. According to the method described by previous study (Levine et al., 1990), protein carbonyl which is a marker of protein oxidation, was measured spectrophotometerically (UV $160 \mathrm{~A}$, Shidmazu, Japan) at $360 \mathrm{~nm}$, based on the reaction of carbonyl compounds with 2,4-dinitrophenylhydrazine (DNPH) (Sigma-Aldrich St. Loius, USA). The results were expressed as nmol/ $\mathrm{mg}$ of protein. 


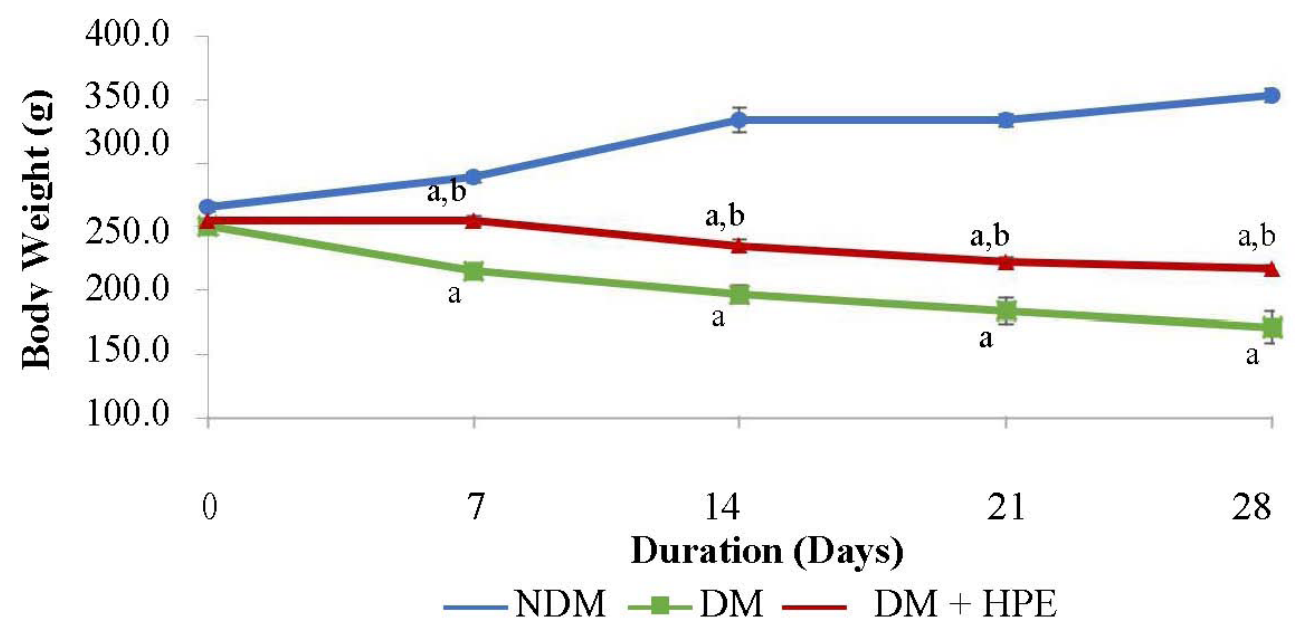

Fig. 1: Body weight between the groups at four weeks of experiment. Values were expressed as mean \pm SEM. Statistical significance for the difference between groups is at $\mathrm{p}<0.05$. ${ }^{\mathrm{a}} \mathrm{p}<0.05$ compared to NDM; ${ }^{\mathrm{b}} \mathrm{p}<0.05$ compared to DM at respective week, $n=8$ for each group.

\section{Antioxidant status}

SOD activity was assayed according to protocol mentioned in previous study (Beyer \& Fridovich, 1987). The reduction of nitro blue tetrazolium (NBT) (ICN Biomedicals, USA) by superoxide anion formed a purple colour of NBT-diformazan, measured with spectrophotometer (UV 160A, Shidmazu, Japan) at $560 \mathrm{~nm}$, in which one unit of SOD inhibits formation of purple formazan by $50 \%$. The results were expressed as E/mg/min. The activity of CAT was measured according to method described by (Aebi, 1984). Decomposition of $\mathrm{H}_{2} \mathrm{O}_{2}$ by CAT was measured using spectrophotometer at $240 \mathrm{~nm}$ for 3 minutes with 30 seconds interval. The results were expressed as $\mathrm{mmol} / \mathrm{min} / \mathrm{mg}$ of protein. GSH was quantified according to the protocols described previously (Ellman, 1959). GSH oxidation by 5,5-dithiobis-2-nitrobenzoic (DTNB) reagent form 5-thionitrobenzoic (TNB) which is yellow-coloured complex, measured at $415 \mathrm{~nm}$ and expressed as $\mathrm{mmol} / \mathrm{mg}$ of protein.

\section{Transmission electron microscopic evaluation}

The microscopic evaluation of the aorta was performed according to the protocol described by previous study (Karasu et al., 1997). Following dissection, the thoracic aorta was cut into small pieces which then fixed at $4^{\circ} \mathrm{C}$ for 2 hours in $2.5 \%$ buffered glutaraldehyde and post-fixed for 90 minutes with osmium tetroxide. Tissues were then dehydrated in ethyl alcohol, followed by propylene oxide, and were embedded in araldite. Semi-thin sections of plastic-embedded samples were stained with toluidine blue, followed by uranyl acetate and lead citrate. The aorta tissues were examined using CM12-Philips transmission electron microscope (Netherlands) equipped with a Mega-View-III digital camera and a Soft Imaging System (Germany) for a computerized acquisition of images.

\section{Statistical analysis}

Statistical analysis was done using Statistical Package for the Social Sciences (SPSS) version 23. The data were analysed using one-way analysis of variance (ANOVA), followed by posthoc Tukey test to estimate the significance differences between groups. Differences were statistically significant at $p<0.05$. Data were then expressed as mean \pm standard error of mean (SEM).

\section{RESULTS AND DISCUSSION}

\section{Effects of HPE on body weight and blood glucose}

At the end of the experiment period, both diabetic groups demonstrated significant decrease in body weight $(\mathrm{p}<0.05)$ compared to NDM group, however the weight of animals from DM + HPE groups were significantly higher compared to DM groups at $\mathrm{p}<0.05$. (Figure 1). Conversely, the blood glucose level in DM + HPE group was significantly lower $(\mathrm{p}<0.05)$ compared to DM group (Figure 2).

STZ-induced diabetes is a well-established diabetic rat model, where the mechanism involves DNA fragmentation, nitric oxide (NO) and free radicals production which then lead to pancreatic $\beta$ cells damage followed by reduction in insulin secretion (Eleazu et al., 2013). In diabetes, reduced body weight is due to loss of proteins and lipid as a result of proteolysis and lipolysis (Hebert \& Nair, 2010). The body weight in diabetic rats was significantly decreased compared to normal rat, as shown in previous study (Almeida et al., 2012). The diabetic rat group showed a consistent higher blood glucose level as expected (Cheng et al., 2013), while aqueous extract of $H$. sabdariffa (HSE) was shown to successfully reduce the blood glucose level significantly probably due to polyphenols are well known as hypoglycaemic agents (Ojulari et al., 2014; Rosemary et al., 2014). 


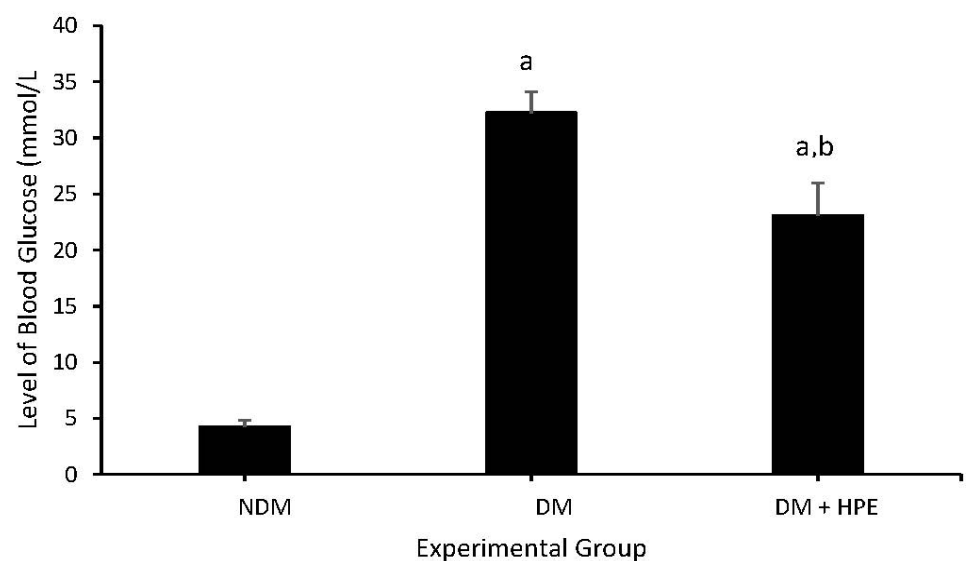

Fig. 2: Level of plasma glucose in NDM, DM and DM + HPE groups after four weeks of study. Data are represented as the mean \pm SEM. Statistical significance for the difference between groups is at $\mathrm{p}<0.05$. ${ }^{\mathrm{a}} \mathrm{p}<0.05$ compared to NDM group, ${ }^{\mathrm{b}} \mathrm{p}<0.05$ compared to $\mathrm{DM}, n=8$ for each group.

Table 1: Oxidative stress markers and antioxidant status in NDM, DM and DM + HPE groups after four weeks of study.

\begin{tabular}{lccc}
\hline & & Group & Darameters \\
\cline { 2 - 4 } & NDM & $44.56 \pm 4.64^{\mathrm{a}}$ & $23.02 \pm 2.42^{\mathrm{a}, \mathrm{b}}$ \\
\hline TBARS $(\mathrm{nmol} / \mathrm{mg})$ & $11.38 \pm 1.18$ & $27.95 \pm 2.07^{\mathrm{a}}$ & $15.48 \pm 0.92^{\mathrm{a}, \mathrm{b}}$ \\
PC (nmol/mg) & $3.52 \pm 0.41$ & $230.78 \pm 8.88^{\mathrm{a}}$ & $631.31 \pm 30.01^{\mathrm{a}, \mathrm{b}}$ \\
SOD (E/mg/min) & $957.34 \pm 56.70$ & $50.27 \pm 3.93^{\mathrm{a}}$ & $78.43 \pm 2.33^{\mathrm{a}, \mathrm{b}}$ \\
CAT (mmol/min/mg) & $144.46 \pm 4.28$ & $0.06 \pm 0.004^{\mathrm{a}}$ & $0.08 \pm 0.004^{\mathrm{a}, \mathrm{b}}$ \\
GSH (mmol/mg) & $0.11 \pm 0.01$ & & DPE \\
\hline
\end{tabular}

Data are represented as the mean \pm SEM. Statistical significance for the difference between groups is at $\mathrm{p}<0.05 .{ }^{\mathrm{a}} \mathrm{p}<0.05$ compared to NDM group, ${ }^{\mathrm{b}} \mathrm{p}<0.05$ compared to DM, $n=8$ for each group.

\section{Effects of HPE on plasma lipid}

In diabetic condition, elevation of blood lipid is one of the risk factor for various cardiovascular complications (Rask-Madsen \& King, 2013). The present study has shown that STZ-induced diabetes rats causing dyslipidaemia as similarly seen in previous study (Lenzen, 2008). The alteration in blood profile could be due to reduced lipoprotein lipase (LPL) activity secondary to the lowering of plasma insulin levels (Kondo et al., 2007). HPE supplementation prevented the increase of triglyceride, total cholesterol and LDL-C significantly $(\mathrm{p}<0.05)$, however it promoted the increment of HDL-C levels in DM + HPE group compared to DM group (Figure 3a-3d). Previously, HSE was shown to reduce serum cholesterol in human (T-L Lin et al., 2007).

\section{Effects of HPE on oxidative stress status of thoracic aorta}

The level of MDA and protein carbonyl in both diabetic groups were significantly higher $(\mathrm{p}<0.05)$ compared to the NDM group. However, HPE managed to significantly reduce $(p<0.05)$ the level of MDA and PC in DM + HPE group compared to DM group (Table 1). Lipid peroxidation can affect the integrity and membrane permeability as well as inhibit the metabolic processes (Li et al., 2014). Interaction between excessive ROS such as $\mathrm{O}_{2}^{-}$and $\mathrm{H}_{2} \mathrm{O}_{2}$ with polyunsaturated fatty acids (PUFA) has been reported in the aorta of diabetic rat which lead to the production of MDA and therefore cause vascular dysfunction (Paneni et al., 2013). The antioxidant properties in Roselle could significantly protect lipid peroxidation by promoting antioxidant status in diabetic condition. Diabetic rats supplemented with HSE showed a significantly lower MDA level (Ramalingam et al., 2016) which suggested that Roselle which is rich in polyphenols, such as catechin, may play a role in reducing the levels of MDA by acting as a free radical scavenger (Pandey \& Rizvi, 2009).

Free radicals are known to induce protein modification which could also affect cellular functions, mechanisms of signal transduction, enzymatic activity, thermal stability, proteolysis and aging acceleration process (Mohammed et al., 2015). In this study, protein carbonyl, a marker of protein oxidation, was elevated in diabetic rats as supported by previous finding (Sushma et al., 2013). Nevertheless, ethanol extracts of HSE supplementation decrease the protein carbonyl level and this is in agreement with the previous study, that Roselle effectively decrease protein oxidation in renal and hepatic tissues of diabetic rats (Farombi \& Ige, 2007). In addition, polyphenols in $H$. sabdariffa was shown to reduce oxidative damage of kidney and improve diabetic nephropathy condition (Lee et al., 2009).

\section{Effect of HPE on antioxidant status (SOD, CAT \& GSH) of thoracic aorta}

Table 1 shows a significantly low activity of SOD and CAT as well as GSH $(p<0.05)$ in the thoracic aorta of DM group compared to NDM group. However, supplementation of HPE managed to restore SOD, CAT and GSH status significantly $(\mathrm{p}<0.05$ ) compared to DM group. 
SOD is an antioxidant enzyme that catalyses the conversion of anion superoxide $\left(\mathrm{O}_{2}{ }^{\circ}\right)$ into oxygen $\left(\mathrm{O}_{2}\right)$ and $\mathrm{H}_{2} \mathrm{O}_{2}$ and CAT completing detoxification process initiated by SOD. The lower activities of SOD and CAT found in diabetic rats is in agreement with the previous studies (Alpsoy et al., 2014; Jemai \& Sayadi, 2015). This was probably due to the increment of antioxidant enzyme usage to compensate with the increased production of ROS. Roselle was suggested to increase the antioxidant activity which then lead to reduction of oxidative damage (Mossalam et al., 2011) and this could possibly due to presence of anthocyanin (Peng et al., 2011). This has been proven in the present study that showed significantly higher SOD and CAT activities in diabetic rats supplemented with HPE.
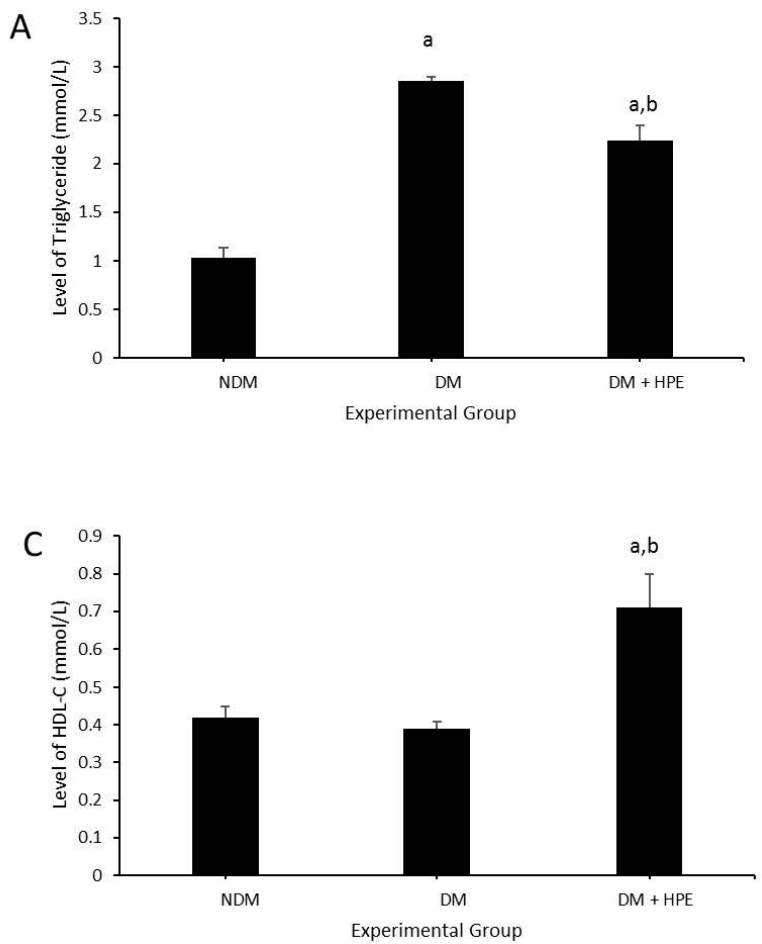

Moreover, diabetic rats also showed a significantly lower in GSH level which is consistent with the previous study (Kumarappan et al., 2012). Decrease in GSH levels could be due to the overused of GSH as an antioxidant in order to cope with oxidative stress that is usually associated with chronic hyperglycaemia. Roselle is known to have rich source of polyphenol (Mercado-Mercado et al., 2015) and it was found to increase $\gamma$-glutamylcysteine synthetase $(\gamma \mathrm{GCS})$ expression. Therefore, it could cause a significant higher GSH level as seen in diabetic rats with HPE supplementation. This mechanism maybe responsible in the synthesis of glutathione thus increased the intracellular GSH content (Moskaug et al., 2005).


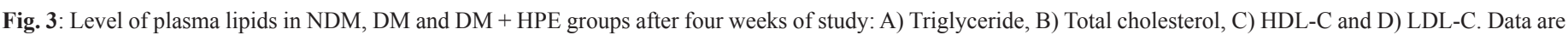

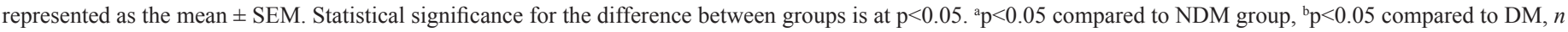
$=8$ for each group.

\section{Electron microscopic observation}

Observation by electron microscope demonstrated a normal structure of the aorta in NDM rats. A regular feature of vascular smooth muscle (VSMC), endothelial cell, internal elastic lamina and the extracellular matrix was observed (Figure 4A). However, in DM rats (Figure 4B), the disruption of regular aorta feature is shown by intimal thickening, fragmented of VSMC together with atrophy of endothelial cell and irregular feature of tunica intima. It was also evidenced by VSMC proliferation and migration from the tunica media towards tunica intima by the disruption of internal elastic lamina. Excess extracellular matrix with electron-densed amorphous material frequently observed in this condition. HPE treatment in diabetic rats seemed to reduce the morphological changes by showing a regular appearance of VSMC and endothelial cell together with reduced VSMC proliferation (Figure 4C).

The HPE treatment has been proven to improve blood glucose level and decreased oxidative stress which lead to reduction of ROS production. According to previous study, the antioxidant agent would protect the aorta from further oxidative damage (Rietjens et al., 2007). This condition would then inhibit the ultrastructural changes of aorta thus prevent the development of atherosclerotic lesion as shown in our study. The present study has shown that disrupted aortic ultrastructure has been improved in this finding, in line with previous study that showed endothelium injury impairment by ROS could be restored by antioxidants (Mugge et al., 1991). 

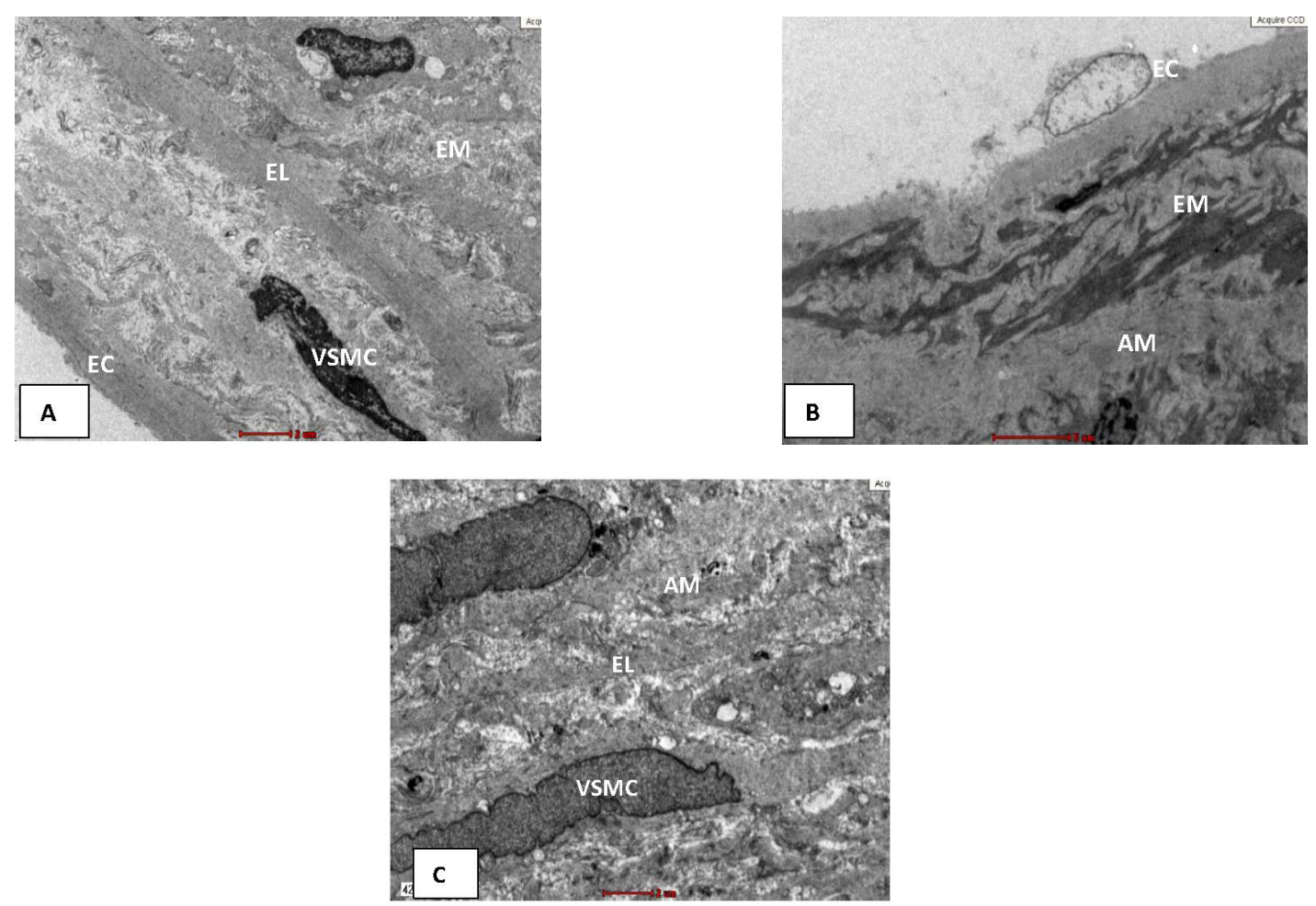

Fig. 4: Electron micrograph of thoracic aorta of rats from NDM groups (A), DM group (B) and DM + HPE group (C) at $x 4400$ magnification. (A) The media layer is composed mainly normal appearance of vascular smooth muscle cells (VSMC), elastic lamina (EL), endothelial cell (EC) and extracellular matrix (EM). (B) Proliferation and fragmentation of VSMC in both the intima and media layer. Fragmented VSMC migrated from the media into the intima, breaking through the EL. The extracellular matrix also consists of amorphous material (AM) in the media layer and the EC became atrophic. (C) The EL and VSMC appeared to be more regular and VSMC did not show proliferation activity.

\section{CONCLUSION}

It is concluded that Hibiscus sabdariffa Linn. shows potential as an anti-diabetic and anti-hyperlipidaemia by reducing blood glucose levels and improving lipid profile in diabetic rats. It is also shown that HPE decreased oxidative stress markers, and simultaneously increased the antioxidant enzymes, thus preventing oxidative stress and ultrastructure damage in the aorta.

\section{AUTHOR CONTRIBUTIONS}

SBB and SZ were the supervisors. NAF, TNT and NLY performed the experiments. NMA wrote and edited the manuscript.

\section{CONFLICT OF INTEREST}

The authors declare that they have no conflict of interests.

\section{ACKNOWLEDGEMENTS}

This project was financially supported by Ministry of Higher Education Malaysia (FRGS/2/2014/SG03/UKM/02/2).

\section{REFERENCES}

Aebi, H. Catalase in vitro. Methods Enzymol, 1984; 105: 121-126. Almeida, DATd, Braga, CP, Novelli, ELB, \& Fernandes, AAH. Evaluation of lipid profile and oxidative stress in STZ-induced rats treated with antioxidant vitamin. Brazilian Archives of Biology and Technology, 2012; 55: 527-536.

Alpsoy, S, Kanter, M, Aktas, C, Erboga, M, Akyuz, A, Akkoyun, DC, \& Oran, M. Protective effects of onion extract on cadmium-induced oxidative stress, histological damage, and apoptosis in rat heart. Biol Trace Elem Res, 2014; 159: 297-303.

Bagri, P, Ali, M, Aeri, V, Bhowmik, M, \& Sultana, S. Antidiabetic effect of Punica granatum flowers: effect on hyperlipidemia, pancreatic cells lipid peroxidation and antioxidant enzymes in experimental diabetes. Food Chem Toxicol, 2009; 47: 50-54.

Beckman, JA, Paneni, F, Cosentino, F, \& Creager, MA. Diabetes and vascular disease: pathophysiology, clinical consequences, and medical therapy: part II. Eur Heart J, 2013; 34: 2444-2452.

Beyer, WF, \& Fridovich, I. Assaying for superoxide dismutase activity: Some large consequences of minor changes in conditions. Anal Biochem, 1987; 161: 559-566.

Brownlee, M. The pathobiology of diabetic complications: a unifying mechanism. Diabetes, 2005; 54: 1615-1625.

Cheng, D, Liang, B, \& Li, Y. Antihyperglycemic Effect of Ginkgo biloba Extract in Streptozotocin-Induced Diabetes in Rats. BioMed Research International, 2013; 2013: 7.

Dokken, BB. The Pathophysiology of Cardiovascular Disease and Diabetes: Beyond Blood Pressure and Lipids. Diabetes Spectrum, 2008; 21: 160-165.

Eleazu, CO, Eleazu, KC, Chukwuma, S, \& Essien, UN. Review of the mechanism of cell death resulting from streptozotocin challenge in experimental animals, its practical use and potential risk to humans. Journal of Diabetes and Metabolic Disorders, 2013; 12: 60-60.

Ellman, GL. Tissue sulfhydryl groups. Archives of Biochemistry and Biophysics, 1959; 82: 70-77.

Farombi, EO, \& Ige, OO. Hypolipidemic and antioxidant effects of ethanolic extract from dried calyx of Hibiscus sabdariffa in alloxan-induced diabetic rats. Fundam Clin Pharmacol, 2007; 21: 601-609.

Friedewald, WT, Levy, RI, \& Fredrickson, DS. Estimation of the concentration of low-density lipoprotein cholesterol in plasma, without use of the preparative ultracentrifuge. Clin Chem, 1972; 18: 499-502. 
Hebert, SL, \& Nair, KS. Protein and energy metabolism in type 1 diabetes. Clin Nutr, 2010; 29: 13-17.

Herranz-Lopez, M., Fernandez-Arroyo, S., Perez-Sanchez, A., Barrajon-Catalan, E., Beltran-Debon, R., Menendez, J.A., Alonso-Villaverde, C, Segura-Carretero, A., Joven, J., \& Micol, V. Synergism of plant-derived polyphenols in adipogenesis: perspectives and implications. Phytomedicine, 2012; 19: 253-261.

Inzucchi, S., Bergenstal, R, Fonseca, V, Gregg, E, Davis, BM, Spollett, G, \& Wender, R. Diagnosis and Classification of Diabetes Mellitus. Diabetes Care, 2010; 33: S62-S69.

Jemai, H. \& Sayadi, S. Heart Histopathology and Oxidative Features in Diabetic Rats and Protective Effects of Oleuropein. Advances in Bioscience and Biotechnology, 2015; Vol.06No.06: 7.

Joshi, H, \& Parle, M. Nootropic Activity of Calyces of Hibiscus sabdariffa Linn Iranaian Journal of Pharmacology and Therapeutics, 2006; 5: $15-20$.

Karasu, C, Ozansoy, G, Bozkurt, O, Erdogan, D, \& Omeroglu, S. Antioxidant and triglyceride-lowering effects of vitamin $\mathrm{E}$ associated with the prevention of abnormalities in the reactivity and morphology of aorta from streptozotocin-diabetic rats. Antioxidants in Diabetes-Induced Complications (ADIC) Study Group. Metabolism, 1997; 46: 872-879.

Kondo, HU, Kiyose, C, Ohmori, R, Saito, H, Tagughi, C, \& Kishimoto, Y. Improves lipoprotein metabolism in humans. Journal of. Nutritional Science and Vitaminology, 2007; 53: 345-348.

Kumarappan, CT, Thilagam, E, Vijayakumar, M, \& Mandal, SC Modulatory effect of polyphenolic extracts of Ichnocarpus frutescens on oxidative stress in rats with experimentally induced diabetes. The Indian Journal of Medical Research, 2012; 136: 815-821.

Lee, WC, Wang, CJ, Chen, YH, Hsu, JD, Cheng, SY, Chen, HC, \& Lee, HJ. Polyphenol extracts from Hibiscus sabdariffa Linnaeus attenuate nephropathy in experimental type 1 diabetes. J Agric Food Chem, 2009; 57: 2206-2210.

Lenzen, S. The mechanisms of alloxan- and streptozotocin-induced diabetes. Diabetologia, 2008; 51: 216-226.

Levine, RL, Garland, D, Oliver, CN, Amici, A, Climent, I, Lenz, AG, Ahn, BW, Shaltiel, S, \& Stadtman, ER. Determination of carbonyl content in oxidatively modified proteins. Methods Enzymol, 1990; 186: 464478 .

Li, AN, Li, S, Zhang, YJ, Xu, XR, Chen, YM, \& Li, HB. Resources and biological activities of natural polyphenols. Nutrients, 2014 6: 6020-6047.

Lin, H-H, Chan, K-C, Sheu, J-Y, Hsuan, S-W, Wang, C-J, \& Chen, J-H. Hibiscus sabdariffa leaf induces apoptosis of human prostate cancer cells in vitro and in vivo. Food Chemistry, 2012; 132: 880-891.

Lin, T-L, Lin, H-H, Chen, C-C, Lin, M-C, Chou, M-C, \& Wang, C-J. Hibiscus sabdariffa extract reduces serum cholesterol in men and women. Nutrition Research, 2007; 27: 140-145.

Mahadevan, N, Shivali, \& Kamboj, P. Hibiscus sabdariffa Linn. - An overview. Indian Journal of Natural Products and Resources, 2009; 8: 77-83.

Maritim, AC, Sanders, RA, \& Watkins, JB, 3rd. Diabetes, oxidative stress, and antioxidants: a review. J Biochem Mol Toxicol, 2003; 17: 24-38.

Mercado-Mercado, G, Blancas-Benitez, FJ, Velderrain-Rodríguez, GR, Montalvo-González, E, González-Aguilar, GA, Alvarez-Parrilla, E, \& Sáyago-Ayerdi, SG. Bioaccessibility of polyphenols released and associated to dietary fibre in calyces and decoction residues of Roselle (Hibiscus sabdariffa L.). Journal of Functional Foods, 2015; 18: 171-181.

Mohammed, MT, Mohammed Kadhim, S, Noori Jassimand, AM, \& Abbas, SI. Free radicals and human health. International Journal of Innovation Sciences and Research, 2015; 4: 218-223.

Moskaug, JO, Carlsen, H, Myhrstad, MC, \& Blomhoff, R. Polyphenols and glutathione synthesis regulation. Am J Clin Nutr, 2005; 81: 277s-283s.

Mossalam, HH, Aty, OAAE, Morgan, EN, Youssaf, SMS, \& Mackawy, AMH. Biochemical and Ultra Structure Studies of the Antiox- idant Effect of Aqueous Extract of Hibiscus Sabdariffa on the Nephrotoxicity Induced by Organophosphorous Pesticide (Malathion) on the Adult Albino Rats. Journal of American Science, 2011; 8: 61-74.

Mugge, A, Elwell, JH, Peterson, TE, Hofmeyer, TG, Heistad, DD, \& Harrison, DG. Chronic treatment with polyethylene-glycolated superoxide dismutase partially restores endothelium-dependent vascular relaxations in cholesterol-fed rabbits. Circ Res, 1991; 69: 1293-1300.

Ojulari, L, Oyeniyi, R, \& Owoyele, B. Effect of Hibiscus sabdariffa on Blood Glucose and Serum Electrolytes in Rats. Journal of Dental and Medical Sciences 2014; 13: 60-62.

Olalye, MT, \& Rocha, JB. Commonly used tropical medicinal plants exhibit distinct in vitro antioxidant activities against hepatotoxins in rat liver. Exp Toxicol Pathol, 2007; 58: 433-438.

Pandey, KB, \& Rizvi, SI. Plant polyphenols as dietary antioxidants in human health and disease. Oxidative Medicine and Cellular Longevity, 2009; 2: 270-278.

Paneni, F, Beckman, JA, Creager, MA, \& Cosentino, F. Diabetes and vascular disease: pathophysiology, clinical consequences, and medical therapy: part I. Eur Heart J, 2013; 34: 2436-2443.

Peng, CH, Chyau, CC, Chan, KC, Chan, TH, Wang, CJ, \& Huang, CN. Hibiscus sabdariffa polyphenolic extract inhibits hyperglycemia, hyperlipidemia, and glycation-oxidative stress while improving insulin resistance. J Agric Food Chem, 2011; 59: 9901-9909.

Ramalingam, A, Budin, SB, Lim, YC, Lislivia, SYN, \& Zainalabidin, S. Dietary UKMR-1 Roselle supplementation prevents nicotine-induced cardiac injury by inhibiting myocardial oxidative stress. Sains Malaysiana, 2016; 45: 1131-1137.

Rask-Madsen, C, \& King, GL. Vascular complications of diabetes: mechanisms of injury and protective factors. Cell Metab, 2013; 17 20-33.

Rietjens, SJ, Bast, A, de Vente, J, \& Haenen, GR. The olive oil antioxidant hydroxytyrosol efficiently protects against the oxidative stress-induced impairment of the NObullet response of isolated rat aorta. Am J Physiol Heart Circ Physiol, 2007; 292: H1931-1936.

Rosemary, Haro, G, \& Rosidah. Antidiabetic Effect of Roselle Calyces Extract (Hibiscus Sabdariffa L.) in Streptozotocin Induced Mice International Journal of PharmTech Research, 2014; 6: 1703-1711.

Stocks, J, \& Dormandy, TL. The Autoxidation of Human Red Cell Lipids Induced by Hydrogen Peroxide. British Journal of Haematology, 1971; 20: 95-111.

Sushma, N, Smitha, PV, Gopal1, YV, Vinay, R, Reddy, NS, Mohan, CH, \& Butchi, AR. Antidiabetic, Antihyperlipidemic and Antioxidant Activities of Buchanania lanzan Spreng Methanol Leaf Extract in Streptozotocin-Induced Types I and II Diabetic Rats. Tropical Journal of Pharmaceutical Research, 2013; 12: 221-226.

Upston, JM, Witting, PK, Brown, AJ, Stocker, R, \& Keaney, JF. Effect of vitamin $\mathrm{E}$ on aortic lipid oxidation and intimal proliferation after arterial injury in cholesterol-fed rabbits. Free Radical Biology and Medicine, 2001; 31: 1245-1253.

Valko, M, Leibfritz, D, Moncol, J, Cronin, MT, Mazur, M, \& Telser, J. Free radicals and antioxidants in normal physiological functions and human disease. Int J Biochem Cell Biol, 2007; 39: 44-84.

How to cite this article:

Zainalabidin S, Budin SB, Anuar NNM, Yusoff NA, Yusof NLM. Hibiscus sabdariffa Linn improves the aortic damage in diabetic rats by acting as antioxidant. J App Pharm Sci, 2018; 8 (01): 108-114. 